\title{
Chilling Injury Investigation by Non- Destructive Measuring Methods during Banana Cold Storage
}

\author{
TAMÁs ZSOM1 ${ }^{*}$, Edina STROHMAYER ${ }^{1}$, LIEN PHUONG Le NGUYEN ${ }^{1,2}$, \\ GÉZA HITKA ${ }^{1}$, VIKTÓRIA ZSOM-MUHA ${ }^{3}$
}

\begin{abstract}
Banana is a really chilling injury sensitive product. Its sensitivity to cold temperatures generates serious practical, economical and commercial problems. Chilling injury related physiological responses of Cavendish type green banana samples stored at $2.5,5,10^{\circ} \mathrm{C}$ and near optimal $\left(15^{\circ} \mathrm{C}\right)$ cold storage temperature were investigated by nondestructive optical methods (surface color and chlorophyll fluorescence measurement, DA-index ${ }^{\circledR}$ evaluation) and by the determination of the physiological reactions (respiration, ethylene production, symptom manifestation) during cold storage and the 8-day long subsequent shelf-life. The positive effects of low temperature storage were proven on mass loss, respiration and ethylene production. In case of bananas stored at $2.5-10{ }^{\circ} \mathrm{C}$, the chilling injury related changes in chlorophyll content related DA-index ${ }^{\circledR}$, IR-values; $F_{m}$ and $F_{v}$ chlorophyll fluorescence values, the $L^{*}, a^{*}, b^{*}, C^{*}$ and hue angle color characteristics suggested clearly from day 3 the onset of chilling injury several days before the visible signs of chilling injury appeared.
\end{abstract}

Keywords: chlorophyll fluorescence, DA-index ${ }^{\circledR}$, respiration, ethylene, low temperature.

\section{Introduction}

Cavendish type banana (Musa acuminata cv. Cavendish L.) is one of the major horticultural products of the world providing an enormous amount of produce throughout the world yearly. Due to the huge distances and long shipping time, proper storage conditions - primarily cooling and relative humidity - during refrigerated transport are the major factors affecting

\footnotetext{
${ }^{*}$ Corresponding author. E-mail: Zsom.Tamas@etk.szie.hu

1Szent István University, Faculty of Food Science, Department of Postharvest Science and Sensory Evaluation, Ménesi út 43-45, Budapest H-1118, Hungary

${ }^{2}$ Biotechnology and Food Technology Institute, Industrial University of Ho Chi Minh City, Ho Chi Minh, Vietnam

${ }^{3}$ Szent István University, Faculty of Food Science, Department of Physics and Control, Somlói út 14-16, Budapest H-1118, Hungary
} 
quality. Due to its physiology and origin, among improper cold storage conditions mature green banana fruits easily suffer a chilling injury $(\mathrm{CI})$ called physiological damage with its unique visible symptoms (smoky peel surface discoloration, dark-brown streaked subepidermal tissue discoloration, failure to ripen, and in severe cases, flesh browning), mainly depending on the exposure time and sensitivity to chilling temperatures under CI threshold of $13-14{ }^{\circ} \mathrm{C}$ (Kader, 2016). Objective and quantitative methods for quality assessment are required for quality control of horticultural products (Zsom-Muha and Felföldi, 2007). Chlorophyll content and chlorophyll fluorescence related novel non-destructive optical measuring methods offer the possibility to non-invasively characterise fruit responses (e.g. physiological status, stage of maturation - Adams and Demmig-Adams, 2004; DeEll et al., 1999; Ziosi, 2008) to different external stressors (e.g. cold stress induced CI - Hale et al., 2013; Kosson, 2003; Pongprasert et al., 2011; Wright et al., 2010) to quantify or predict produce quality and their postharvest changes (Nedbal et al., 2000; Pinto et al., 2015; Yang et al., 2011). The aim of our research was to observe and monitor the low but not freezing temperatures induced chilling injury phenomena of green-ripe banana by non-destructive measuring methods.

\section{Materials and Methods}

Mature green and fresh Cavendish type bananas (Musa AAA group, Cavendish subgroup, cv. Cavendish L.) were obtained from an experienced banana ripening station (Compagnie Fruitiere Hungary Kft., Hungary) in uniform maturity. According to uniform size, mass, shape and freedom from defects, 60 bananas were randomly divided into four groups. Bananas were stored in temperature controlled refrigerators at $\mathrm{CI}$ inducing temperatures of $2.5 \pm 0.5{ }^{\circ} \mathrm{C}, 5 \pm 0.5^{\circ} \mathrm{C}$ and $10 \pm 0.5^{\circ} \mathrm{C}$. Control samples were cold stored additionally at slightly above optimum, at $15 \pm 0.5^{\circ} \mathrm{C}$. Samples were cold stored for 8 days and subsequently for 8 days of shelflife at $20-22{ }^{\circ} \mathrm{C}$ wrapped in LDPE bags. Six measuring points on the two opposite sides were equally distributed along the banana length: one near the stem-end, one at the middle part and one close to the tip. They were selected for surface color measurements, chlorophyll fluorescence analysis and DA-index ${ }^{\circledR}$ evaluation.

Mass loss (\% of fresh mass) was calculated based upon the measured mass data of each sample on every measuring day. 
For the determination of surface color changes, the CIELAB color characteristics $\left(\mathrm{L}^{*}, \mathrm{a}^{*}, \mathrm{~b}^{*}, \mathrm{C}^{*}\right.$ and $\left.\mathrm{h}^{\circ}\right)$ were measured by a portable Minolta Chroma Meter CR-400 (Minolta Europe GmbH, Germany) with $\varnothing 8 \mathrm{~mm}$ aperture.

Respiration rate as carbon dioxide production was measured for an hour in a closed respiratory system (consisting of four purpose built, hermetically closed plastic containers) equipped with FY A600-CO2H carbon dioxide sensors (0-9999 ppm CO 2 ) connected to an Almemo 3290-8 data logger (Ahlborn Mess-und Regelungstechnik $\mathrm{GmbH}$, Germany). Results were expressed in milliliter of $\mathrm{CO}_{2}$ produced per kilogram of fruit in $1 \mathrm{~h}\left(\mathrm{ml} \mathrm{CO}_{2} \mathrm{~kg}^{-1} \mathrm{~h}^{-1}\right)$. At least 3 samples per group were placed into plastic containers of the respiratory system (4 repetitions per group, day).

Ethylene production was determined by an ICA-56 hand-held ethylene analyzer (International Controlled Atmosphere Ltd., UK) upon the measured ethylene production of the samples being held for about an hour in the above detailed respiratory system. Results were expressed in microliter of ethylene produced per kilogram of fruit in $1 \mathrm{~h}\left(\mu \mathrm{l} \cdot \mathrm{C}_{2} \mathrm{H}_{4}\right.$ $\left.\mathrm{kg}^{-1} \cdot \mathrm{h}^{-1}\right)$.

The chilling injury effected changes of photosynthetic activity, integrity and efficiency of photosystem II (PSII) were characterized by the measurement of chlorophyll fluorescence parameters. $\mathrm{F}_{0}$ (dark fluorescence signal), $F_{m}$ (maximum dark fluorescence signal) and $F_{v}$ (variable fluorescence $F_{v}=F_{m}-F_{0}$ ) parameters at the above mentioned six points of each banana were measured by a PAM WinControl-3 controlled MONIPAM multi-channel chlorophyll fluorometer (Heinz Walz $\mathrm{GmbH}$, Germany). The calculated index of $F_{v} / F_{m}$ reflects the potential maximum photon yield of photochemistry, i.e. the maximum photochemical efficiency. It is a valuable tool to determine both photosynthetic capacity and stability. Hence, it is very suitable to investigate postharvest stress responses and chlorophyll degradation. Additionally, the ratio, $\mathrm{F}_{\mathrm{m}} / \mathrm{F}_{0}$ was also calculated.

In order to characterize the change in fruit surface color or tissue related chlorophyll content, the DA (or $\Delta \mathrm{A}$ ) index ${ }^{\circledR}$ was measured by a FRM01-F type Vis/NIR DA-meter ${ }^{\circledR}$ (Sintéleia s.r.l., Italy) on every six measurement points of the banana samples. This non-destructive maturity index (index of absorbance difference, $\mathrm{I}_{\mathrm{AD}}$ ) created by $\mathrm{G}$. Costa and coworkers (Ziosi et al., 2008) is calculated upon the difference in absorbance between the wavelengths of 670 and $720 \mathrm{~nm}$ near the chlorophyll-a absorption peak. The value of it is proportional to the amount of chlorophyll present in the fruit, and varies from 0 to 5 . For the calculation of it, back light luminosity value (BK), Red light value (RED) and IR light 
value (IR) were also measured automatically by the device according to the handbook of the device.

Data were converted by means of routines in MS-Excel and were analyzed using the SPSS for Windows ver. 14. Statistical analysis was performed at 95\% significance level (in figures marked with 95\% CI).

\section{Results and Discussion}

Concerning the mass loss of the different treatments (Fig. 1), no significant difference was found between the chilling injury inducing temperatures $\left(2.5,5\right.$ and $\left.10^{\circ} \mathrm{C}\right)$. After the $3^{\text {rd }}-4^{\text {th }}$ day, a significant difference was found between samples stored at $15^{\circ} \mathrm{C}$ and the samples stored at and below $10^{\circ} \mathrm{C}$, followed by a steep and significant increase after the removal to shelf-life (after 8 days) conditions with room temperature.

The change of $F_{0}$ fluorescence values (data not shown) showed an insignificant reduction independently from chilling temperatures $\left(2.5-10^{\circ} \mathrm{C}\right)$ until the $3^{\text {rd }}$ day. Between the $3^{\text {rd }}$ and $6^{\text {th }}$ day of storage and later on until the $8^{\text {th }}$ day (removal from the chilling temperatures) at chilling temperatures - especially at $2.5^{\circ} \mathrm{C}$ - a more intensive reduction was

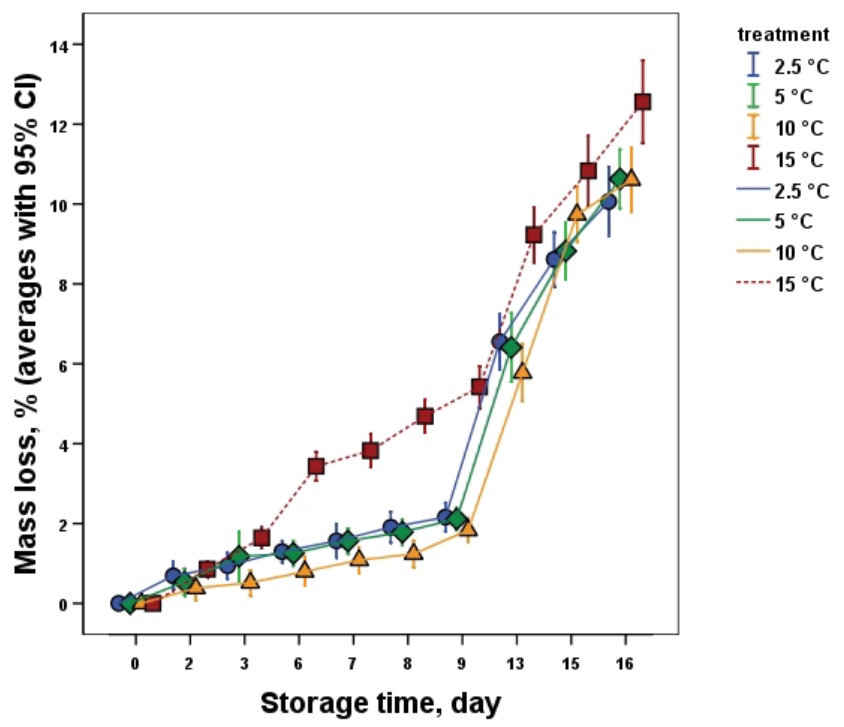

Fig. 1. Change of average mass loss of the banana samples during storage 


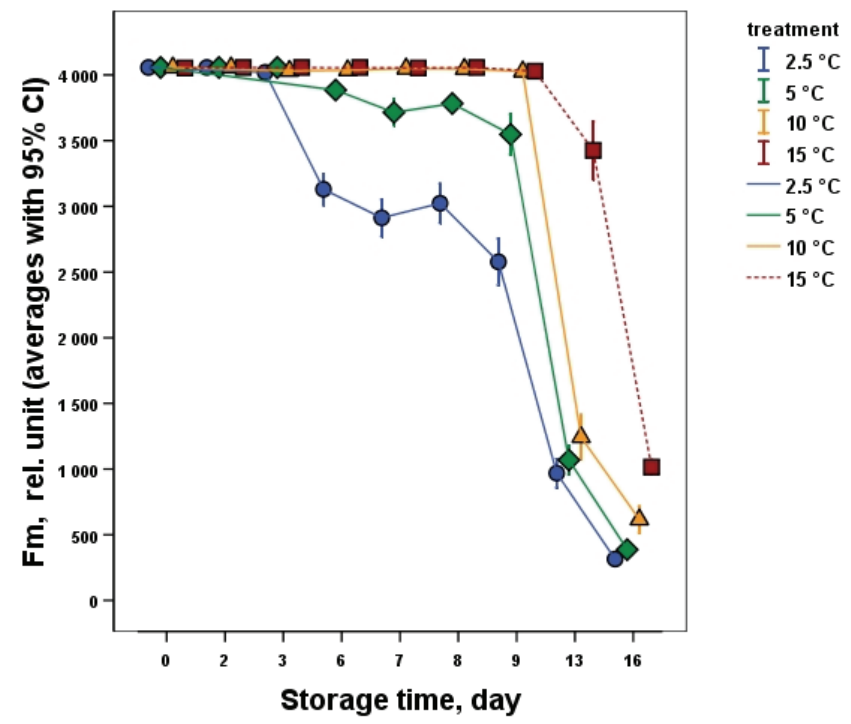

Fig. 2. Change of maximal chlorophyll fluorescence $\left(\mathrm{F}_{\mathrm{m}}\right)$ of the banana samples during storage

observed possibly due to developing chilling injury developing more rapidly from day 8 at room temperature during shelf-life. The same characteristic change was observed in case of maximal $\left(\mathrm{F}_{\mathrm{m}}\right)$ (Fig. 2) and variable fluorescence (data not shown) values $\left(F_{v}\right)$. The chilling temperature dependent significant change was clear from day 3 , clearly suggesting the chilling injury phenomena especially in case of samples stored at $2.5^{\circ} \mathrm{C}$, with lower intensity at the higher chilling injury causing temperatures of 5 and $10{ }^{\circ} \mathrm{C}$. The sharp decrease in the $\mathrm{F}_{\mathrm{m}}$ and $\mathrm{F}_{\mathrm{v}}$ values clearly revealed the chilling injury manifestation after removal from cold to shelf-life conditions from day 8 supported by the pictures taken of the stored samples (data not shown). The samples stored at $15^{\circ} \mathrm{C}$ retained higher photosynthetic activity during the entire storage period even during shelf-life. The average initial $\mathrm{F}_{\mathrm{v}} / \mathrm{F}_{\mathrm{m}}$ fluorescence values (around 0.65 ) represented the mature green and highly photosynthetically active chlorophyll containing intact banana tissue (data not shown). The insignificant change of $F_{v} / F_{m}$ revealed that this index was found to be a less sensible parameter than the $F_{0}, F_{m}$ and $F_{v}$. They appeared to characterize more reliably and sensibly the chilling injury related chlorophyll fluorescence changes during cold storage at chilling injury inducing temperatures $\left(2.5-10^{\circ} \mathrm{C}\right)$. Additionally, after removal to 
shelf-life conditions (from day 9), the $F_{v} / F_{m}$ intensive decline showed chlorophyll fluorescence changes related to the manifestation of chilling injury symptoms induced by the higher temperature.

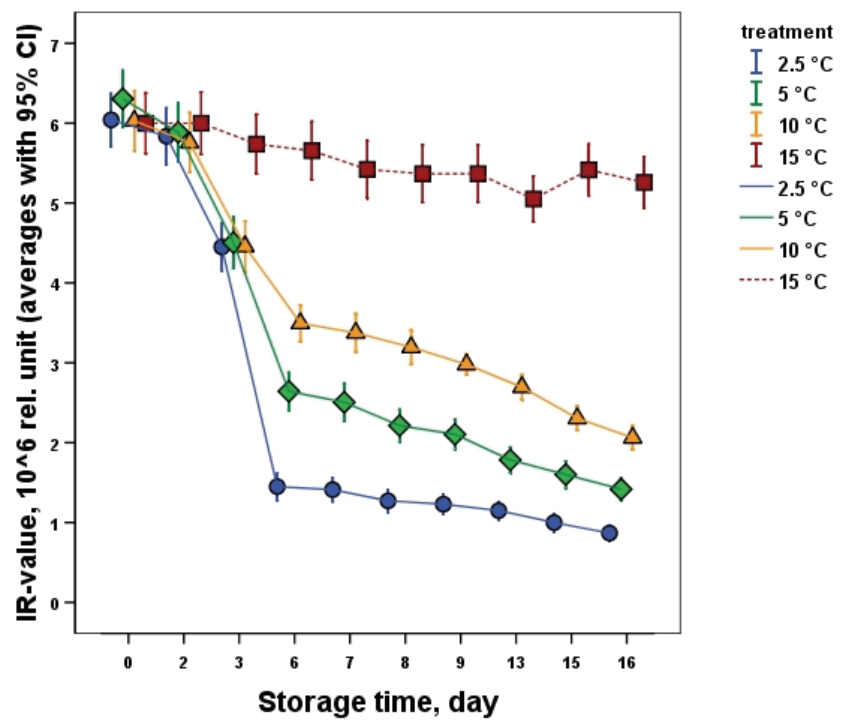

Fig. 3. Change of banana IR-values during storage

From among the of BK, Red (data not shown) and IR values used in the DA index ${ }^{\circledR}$ calculation, only the IR-values showed significant changes (Fig. 3) during storage at chilling injury inducing temperatures $\left(2.5-10{ }^{\circ} \mathrm{C}\right)$. Temperature dependent significant difference was found from the $3^{\text {rd }}$ day of cold storage between the chilling injury inducing low temperatures $\left(2.5-10^{\circ} \mathrm{C}\right)$ and the optimal banana storage temperature suggesting the start of the chilling injury development from the $2^{\text {nd }}$ day. Furthermore, the IRvalues clearly showed the low temperature effect inducing chilling injury from the $3^{\text {rd }}$ day to the $6^{\text {th }}$ day with a temperature dependent steep decline followed by a less intensive reduction until the end of the shelf-life. Based upon the measured basic values of BK, Red and IR, the change of the calculated DA index ${ }^{\circledR}$ values (Fig. 4) showed significant difference between the chilling injury inducing temperatures and control after the 3 rd day and this difference became more pronounced after the removal to the higher temperature shelf-life conditions. 


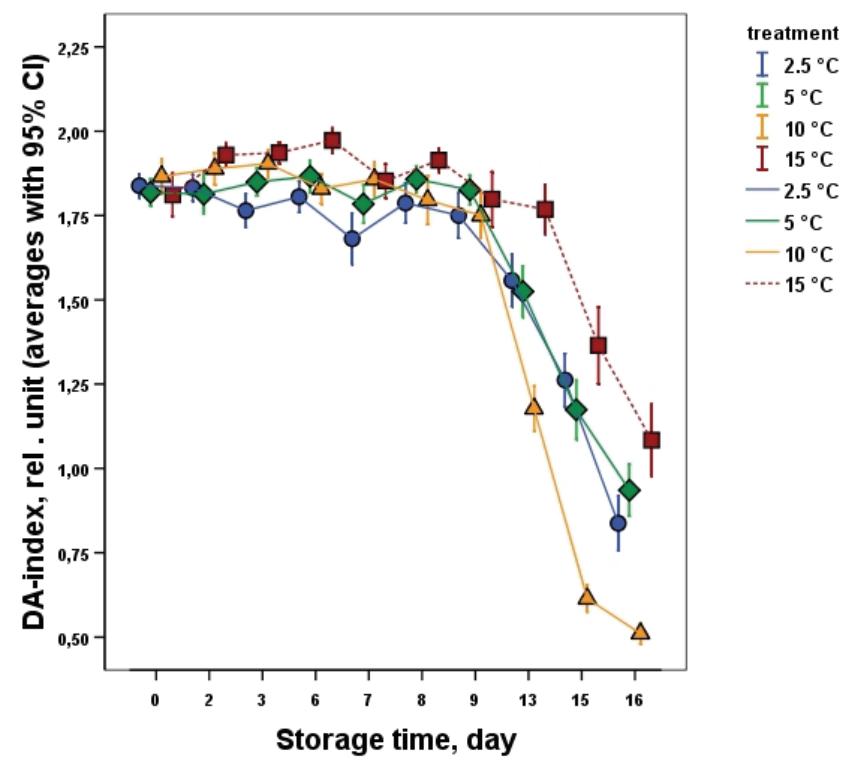

Fig. 4. Change of banana DA index ${ }^{\circledR}$ during storage

In a close connection to the chlorophyll fluorescence parameters' and the change of the DA index ${ }^{\circledR}$ values, the surface color changed clearly representing the effect of chilling injury inducing temperatures on banana color and quality. The $\mathrm{L}^{*}, \mathrm{a}^{*}, \mathrm{~b}^{*}$ (data not shown), $\mathrm{C}^{*}$ (data not shown) and hue angle values clearly and significantly showed the effect of chilling injury inducing temperatures from day 3 , especially in case of 2.5 and $5{ }^{\circ} \mathrm{C}$ (Figs 5-7). In case of $\mathrm{L}^{*}$ values, the smoky banana skin discoloration caused by chilling injury was shown as a steep decline. Significant change was observed in case of the $L^{*}, a^{*}, b^{*}, C^{*}$ and hue angle values between the $3^{\text {rd }}$ and $6^{\text {th }}$ day of cold storage. This difference turned more pronounced between the two lowest $\left(2.5\right.$ and $\left.5^{\circ} \mathrm{C}\right)$ and the higher temperatures of 10 and $15{ }^{\circ} \mathrm{C}$, representing the temperature dependency of chilling injury. From day 9 (after removal from cold to shelf-life conditions), the change of $\mathrm{a}^{*}$ values (Fig. 6) together with $\mathrm{b}^{*}$ values (data not shown) revealed a more intensive surface color change from mature green towards yellow especially in case of samples cold stored at 10 and $15^{\circ} \mathrm{C}$. Control samples stored at $15^{\circ} \mathrm{C}$ stayed green during the entire storage period with no chilling injury. The higher surface color intensities of 10 and $15{ }^{\circ} \mathrm{C}$ by the calculated hue angle values also represented the significant differences between optimal 
and chilling injury inducing temperatures and the observed temperature dependent changes from day 3.

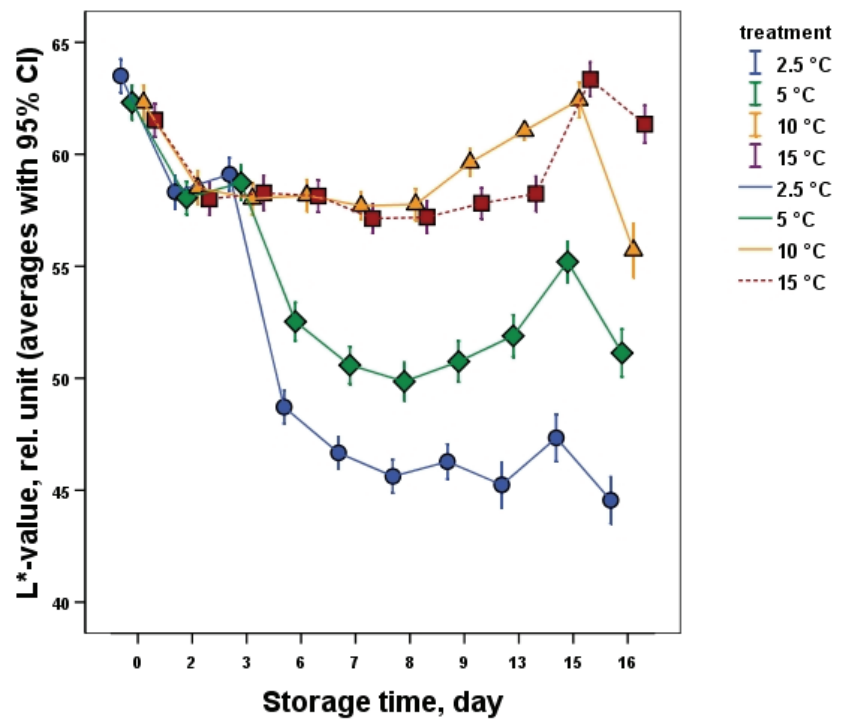

Fig. 5. Change of banana $\mathrm{L}^{*}$ color coordinates during storage

The values of the suppressed respiratory activity (Fig. 8) and ethylene production (data not shown) showed clearly the positive effect of reduced temperature on physiological activity during cold storage. During shelf-life conditions, in accordance with the chilling injury phenomena, both features showed the higher temperature related and induced significant (about five times higher) increase. In case of respiration, huge difference was found near the end of the storage period between the CI treatments and control. No significant difference was found between the chilling injury inducing temperatures. Additionally, the ethylene production only started slowly to develop (data not shown) to a higher level after the removal to shelf-life. Reaching the $16^{\text {th }}$ day, significant difference was found between the control and the samples stored at $10{ }^{\circ} \mathrm{C}$ and the other CI suffered samples. These respiratory and ethylene production changes were mainly due to the mature green state related reduced ability of the green banana to ripe without higher concentration of ethylene from external source and the chilling injury related physiological changes. 


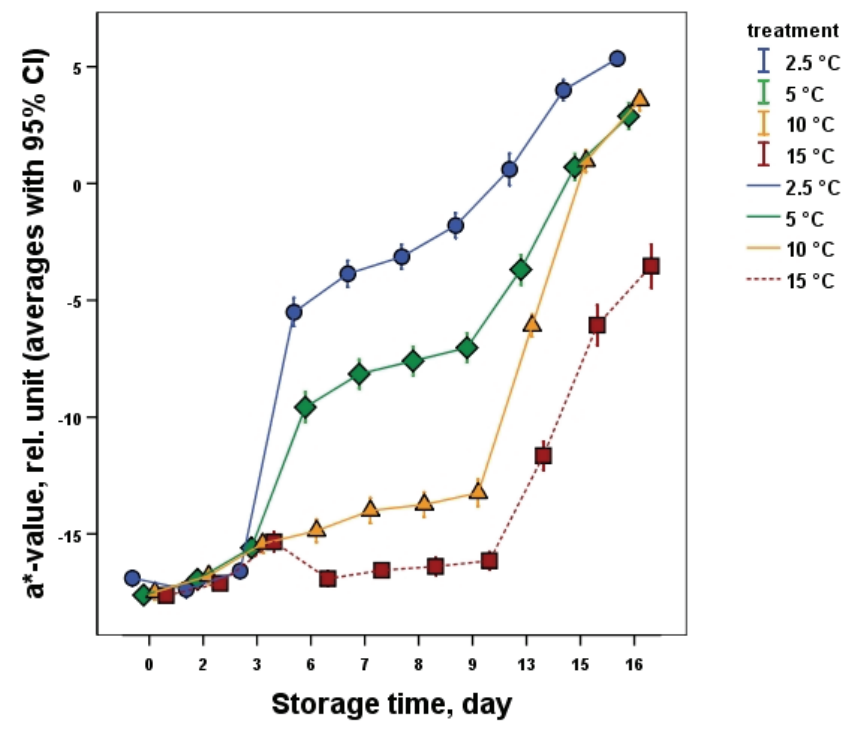

Fig. 6. Change of banana $\mathrm{a}^{*}$ color coordinates during storage

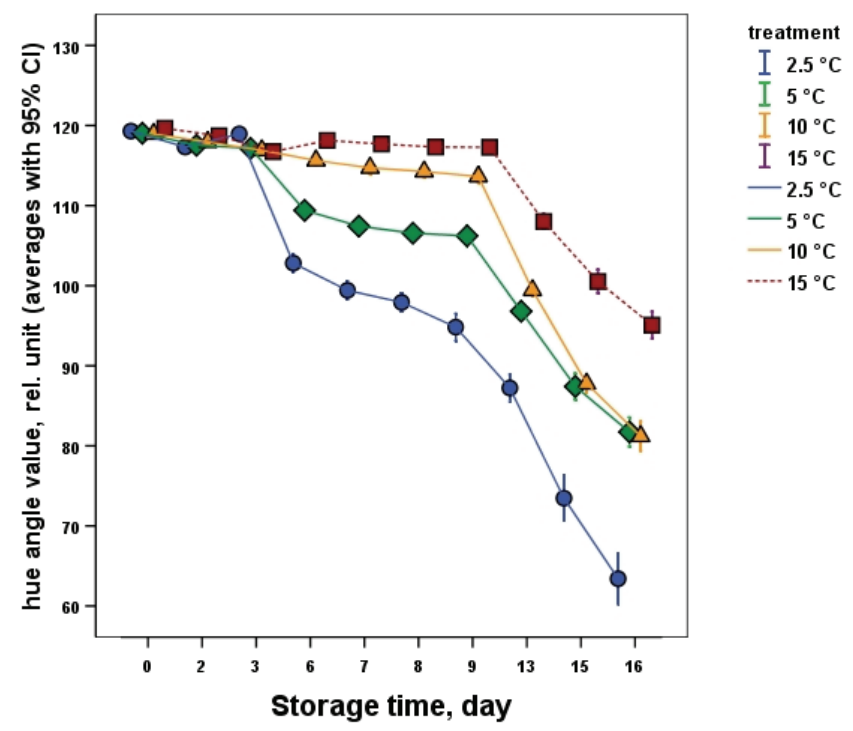

Fig. 7. Change of banana hue angle values during storage 


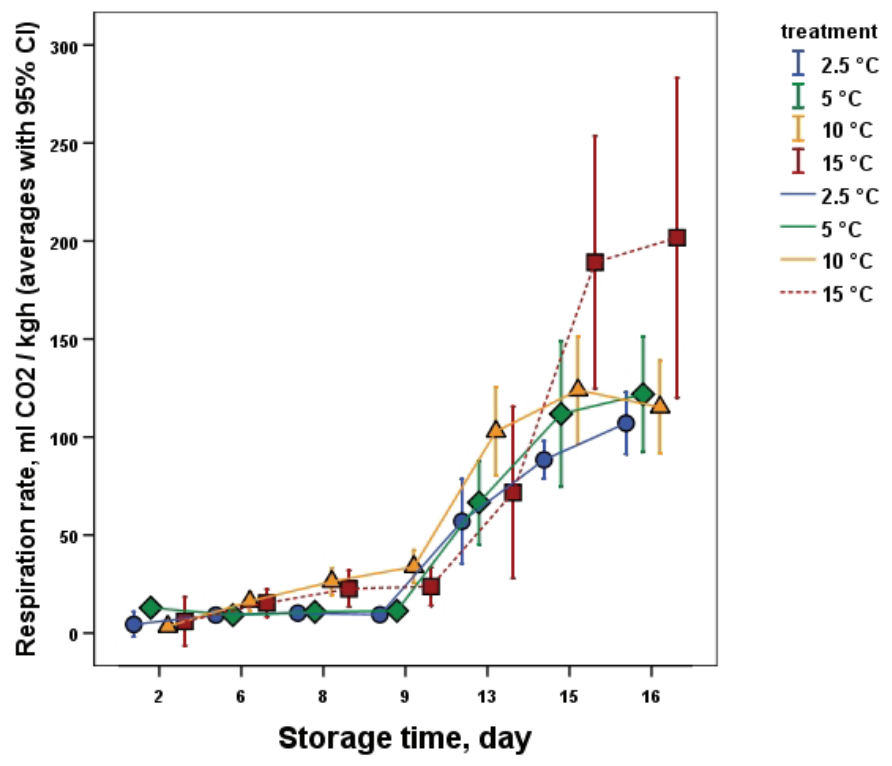

Fig. 8. Changes of respiration rate of the banana samples during storage

The digital pictures taken during the storage period (pictures not shown) revealed clearly that the symptoms of chilling injury of the samples stored at 2,5 and $5{ }^{\circ} \mathrm{C}$ became visible from day 6 as greyish skin discoloration in contrast to the measured chlorophyll fluorescence and DA meter data suggesting the injury development around the $2^{\text {nd }}$ or $3^{\text {rd }}$ day. Remarkably, in case of samples stored at $10^{\circ} \mathrm{C}$, no visible chilling injury symptoms were seen on the skin. In contrast to that, the sub-epidermal tissue injury, the characteristic discoloration of dark-brown longitudinal streaks, emerged soon after the samples were removed to shelf-life conditions of around $20^{\circ} \mathrm{C}$ proving the basic features of chilling injury listed in literature. Samples stored at $15{ }^{\circ} \mathrm{C}$ cold remained mature green throughout the whole cold period showing no signs of chilling injury due to the near to optimal temperature condition. Light yellow coloration was only observed towards the end of the shelf-life period due to the higher temperature induced low intensity postharvest ripening. 


\section{Conclusions}

Chilling injury related physiological responses of mature green banana stored at different chilling injury inducing temperatures $\left(2.5,5\right.$ and $\left.10{ }^{\circ} \mathrm{C}\right)$ and near optimal $\left(15^{\circ} \mathrm{C}\right)$ cold storage temperature were investigated by non-destructive measuring methods. Mass loss change clearly showed the storage temperature dependency with a significant difference between the optimal and chilling inducing temperatures being more pronounced during cold storage. After removal to shelf-life conditions, the mass loss increase of samples stored at $2.5,5$ and $10^{\circ} \mathrm{C}$ showed the same intensity change but with a one day long delay compared to data of $15^{\circ} \mathrm{C}$. From the evaluated chlorophyll fluorescence parameters, the change of $\mathrm{F}_{\mathrm{m}}$ and $\mathrm{F}_{\mathrm{v}}$ values showed reliably the chilling injury related changes, especially with significant differences between the optimal and low temperatures from the $3^{\text {rd }}$ day of cold storage, days before the symptoms of chilling injury became visible. Additionally, the change of parameters related to the chlorophyll content and surface color (i.e. DA index ${ }^{\circledR}$ related IR-value, $\mathrm{L}^{*}, \mathrm{a}^{*}, \mathrm{~b}^{*}, \mathrm{C}^{*}$ and hue $^{\circ}$ values) clearly and significantly represented the negative effect of chilling injury inducing temperatures from about day 3 . These significant changes indicated clearly the onset of the injury several days before the visible signs appeared. The positive effect of reduced temperature was shown as reduced $\mathrm{CO}_{2}$ and ethylene production during cold storage. Lately, during the early days of shelf-life, the higher temperature triggered a cold storage temperature independent slow rise resulting in a significant difference in ethylene production between the two lowest $\left(2.5\right.$ and $\left.5^{\circ} \mathrm{C}\right)$ and the two higher temperature groups. The same was observed in case of respiration, but with a high difference at the end of storage between the control and the cold stored samples. Our results, as chlorophyll fluorescence based early detection of chilling injury of green banana at chilling temperatures, coincide with the results of, e.g., Kosson et al. (2003), obtained for mature green pepper. Additionally, in case of green banana storage at chilling temperatures and subsequent shelf-life, the DA-index ${ }^{\circledR}$ measurement was also found to be suitable for the non-invasive postharvest quality measurement as it was reported, e.g., for peach by Ziosi et al. (2008), Pinto et al. (2015) or for nectarines by Hale et al. (2013). 


\section{Acknowledgement}

The Project is supported by the European Union and co-financed by the European Social Fund (grant agreement no. EFOP-3.6.3-VEKOP-16-201700005).

\section{References}

Adams, W.W., Demmig-Adams, B. (2004) Chlorophyll a Fluorescence (chapter 22) Chlorophyll fluorescence as a tool to monitor plant response to the environment. In: Papageorgiou G.C., Govindjee (eds.) Chlorophyll a fluorescence. Advances in photosynthesis and respiration. Springer, Dordrecht, vol. 19: 583-604.

DeEll, J. R., van Kooten, O., Prange, R. K., Murr, D. P. (1999) Applications of chlorophyll fluorescence techniques in postharvest physiology. Hort. Rev. 23: 69-107.

Hale, G., Lopresti, J., Stefanelli, D., Jones, R., Bonora, L. (2013) Using non-destructive methods to correlate chilling injury in nectarines with fruit maturity. Acta Hortic. 1012: 83-89.

Kader, A.A. (accessed Nov., 2016) Banana: Recommendations for maintaining postharvest quality. http://postharvest.ucdavis.edu/Commodity_Resources/ Fact_Sheets/Datastores/Fruit_English/?uid=9\&ds $=798$

Kosson, R. (2003) Chlorophyll fluorescence and chilling injury of green pepper as affected by storage conditions. Acta Horticulturae 628: 379-385.

Nedbal, L., Soukupová, J., Whitmarsh, J., Trtílek, M. (2001) Postharvest imaging of chlorophyll fluorescence from lemons can be used to predict fruit quality. Photosynthetica 38(4): 571-579.

Pinto, C., Reginato, G., Shinya, P., Mesa, K., Díaz, M., Atenas, C., Infante, R. (2015) Skin color and chlorophyll absorbance: Indices for establishing a harvest date on nonmelting peach. Scientia Horticulturae 192: 231-236.

Pongprasert, N., Sekozawa, Y., Sugaya, S., Gemma, H. (2011) A novel postharvest UV-C treatment to reduce chilling injury (membrane damage, browning and chlorophyll degradation) in banana peel. Scientia Horticulturae 130(1): 73-77.

Yang, X., Song, J., Fillmore, S., Pang, X., Zhang, Z. (2011) Effect of high temperature on color, chlorophyll fluorescence and volatile biosynthesis in green-ripe banana fruit. Postharvest Biology and Technology 62(3): 246-257.

Wright, H., DeLong, J., Harrison, P.A., Gunawardena, A.H., Prange, R. (2010) The effect of temperature and other factors on chlorophyll a fluorescence and the lower oxygen limit in apples (Malus domestica). Postharvest Biology and Technology 55(1): 21-28.

Ziosi, V., Noferini, M., Fiori, G., Tadiello, A., Trainotti, L., Casadoro, G., Costa, G. (2008) A new index based on vis spectroscopy to characterize the progression of ripening in peach fruit. Postharvest Biology and Technology 49(3): 319-329.

Zsom-Muha, V., Felföldi, J. (2007) Vibration behaviour of long shape vegetables. Progress in Agricultural Engineering Sciences 3(1): 21-46.- 